\title{
Suita za mali orkester (1932) Demetrija Žebreta med »starimi« in »novimi« strukturnimi idiomi
}

\section{Suite for Small Orchestra (1932) by Demetrij Žebre Between the "Old" and the "New" Structural Idioms}

Ključne besede: Demetrij Žebre, Suita za mali orkester, slovenska sodobna glasba 20. stoletja, Osterčev krog

\section{IZVLEČEK}

Suita za mali orkester (1932) Demetrija Žebreta je edino orkestralno delo tega skladatelja, ki je nastalo v času študija pri Slavku Ostercu, prvo tehtnejše (večje) delo, ki je vredno obravnave in edinstveno delo v orkestralnem opusu po parodično-satirični vsebini. S predstavljeno analizo skladbe naj bi prek ločene obravnave posameznih strukturnih parametrov med seboj razločili »stare« kompozicijske idiome od »novih« z ozirom na kategorijo »umetniškega« ter v njej razbrali nastavke značilnosti kasnejših Žebretovih orkestralnih skladb. Med slednjimi so variacijskost (razvojnost) melodike in ritmike, inkongruentna metrika, vertikalna in horizontalna polimetrija, polnozvočna orkestracija, "nova« tonalnost, "nova" akordika, »nova« tekstura, enovitost motivično-tematske in siceršnje mnogoterosti ter mojstrstvo strukturiranja (napenjanja) daljših simfoničnih lokov.
Keywords: Demetrij Žebre, Suite for small orchestra, Slovenian toth-century music, Osterc's circle

\section{ABSTRACT}

Demetrij Žebre's Suite for Small Orchestra (1932) is his only orchestral work composed during his period of study with Slavko Osterc and the first piece worthy of extended analysis considering its parodical/satirical nature. With this presented analysis and by the discussion of paticular structural parameters, it will be possible to define the "older" compositional idioms from the "newer" or more "artistic categories of the style which later became a part of Žebre's orchestral opus. Among these categories are his developments of rhythm and melody, his use of incongruous meters, vertical and horizontal combined metrics, fuller orchestration, "new « approaches to tonality, chords and layers, singular use of mono thematics and the use of multi structuring in the longer symphonic phrase.

Kljub nekaj orkestralnim poskusom pred letom $1932^{1}$ je Suita za mali orkester Demetrija Žebreta njegovo prvo tehtnejše delo za orkester, vredno obravnave. Ustvaril jo

1 To so Andante za veliki orkester (1926), Žalostni dnevi za veliki orkester (1927), Žrtveni dar za veliki orkester (1927), Pesem žebljarjev za orkester (1928). Gl. Žebrè - mapa, NUK Ljubljana, Glasbena zbirka. 
je v času študija pri Slavku Ostercu (1929-1934) ${ }^{2}$ in glede na to, da partitura Bacchanala po vsej verjetno (več) ne obstaja, ${ }^{3}$ tudi edina (ohranjena) orkestralna skladba iz tega obdobja. Zanimiva je predvsem zato, ker v celotnem Žebretovem orkestralnem opusu ni sorodne skladbe, s katero bi jo bilo mogoče primerjati. Od vseh izstopa po dosledni čustveni zadržanosti in izrazu karikature ter groteske, značilne za nekatera dela osrednjih predstavnikov novega klasicizma med obema vojnama (Prokofjeva, Stravinskega, Šostakoviča). Objektivistična drža je v določeni meri sicer prisotna tudi pri Teku (1935) in Toccati (1936), vendar v drugačni inačici in z uporabo drugih kompozicijskih postopkov, zato je Suita po vsebnosti kategorije humornega slogovno edinstveno delo. Poleg tega je neposreden odsev Osterčevega pouka, zato se v njej vpliv znamenitega učitelja kaže v najbolj čisti obliki. Ena od teh je (kljub Žebretovi še začetniški skladateljski neizkušenosti in »nebogljenosti«) tudi nekonsistentna kombinacija tradicionalnih in novih strukturnih idiomov.

Prvič je Suito za mali orkester izvedel društveni orkester Preporoda pod taktirko dvajsetletnega skladatelja na slavnostni akademiji Preporoda 16. 12. 1932. ${ }^{4}$ Izvedba kot skladba sáma sta naleteli pri strokovni javnosti na ugoden odmev. Ocena Emila Adamiča je zvenela zelo spodbudno, če ne kar preroško: »Ta društveni orkester [...] je [...] zaigral državno himno, nato pa kompozicijo svojega dirigenta 'Suito v štirih stavkih' za orkester. Sicer je to prvenec Demetrija Žebreta, vendar že tu kaže mladi komponist močno osebno noto, radikalno sodobno orientiranost, smisel za zaokroženo formo, ter predvsem tenak čut za živo, nekako jazzovsko zvočnost orkestra. Predstavil sem ga že svoj čas v 'Novi muziki' javnosti sluteč, da bo iz še tedaj malega dečka zrasel v resnega in tehtnega bodočega slovenskega muzika. Njegova Suita me je v tedanji moji sodbi vnovič prepričala in uverjen sem, da se bodo vanj stavljene nade tudi izpolnile. Kakor rečeno, je društveni orkester mlade, temperamentne borbenosti prekipevajoče delo zaigral kar se da najbolje. " ${ }^{5}$ Za razliko od baleta Dan (današnjega [Bacchanale]), ki ga je skladatelj namenil odrski uprizoritvi, pa je ta v celoti še ni dočakal, so Suito postavili na oder v baletni obliki pod naslovom Cesta 14 . junija leta $1939,{ }^{6}$ v okviru Plesnega večera ljubljanske

2 Obstajajo trije rokopisni zapisi - čistopisi partiture, dva z dodanimi glasovi. Z datumom je opremljena le particella: «26. 9. 1932« ob koncu 1. st., "30. 9. 1932« ob koncu 2. st., »6. 10. 1932« ob koncu 3. st., 17. 10. 1932« ob koncu 4. st. Gl. Žebrè - mapa, NUK Ljubljana, Glasbena zbirka.

3 Rokopisna partitura skladbe, ki jo danes poznamo pod domnevnim naslovom "Bacchanale« in z domnevno letnico nastanka »1933«, pripisanima po skladateljevi smrti "na podlagi avtorjeve skicirke« (Uroš Krek), je domala identična z rokopisno partituro baleta Dan - simfonično sliko v 3 stavkih za veliki orkester, opremljeno z Žebretovimi lastnoročnimi letnicami »1838Ć \$42 (gl. Žebrè - mapa, NUK Ljubljana, Glasbena zbirka). Da je skladbo z naslovom Bacchanale skladatelj ustvaril že leta 1933, drži, saj o tem priča rokopisni osnutek ocene te skladbe Emerika Berana, ki je bil tedaj član izpitne komisije pri Osterčevih učencih iz predmeta kompozicija na Državnem konservatoriju (gl. Zapuščina Beran, Emerik: [osnutek ocene Žebretovega Bacchanale in Suite za mali orkester], Univerzitetna knjižnica Maribor, Glasbena in filmska zbirka). K zelo verjetnemu sklepu, da jo je uničil, pa nas vodi rokopisni zaznamek, da "partitura skladbe Bacchanale ne obstaja na samostojnem listku v zapuščini Ksenije Vidali (hrani Slovenski gledališki muzej). Dodatno nas k temu napeljujejo neizpolnjena mesta pri letnici »1933« v Žebretovih lastnoročnih popisih njegovih skladb. Gl. Žebrè - kronika, NUK Ljubljana, Glasbena zbirka. Več o tem gl. Karmen Salmič Kovačič: Orkestralni opus Demetrija Žebreta. Magistrsko delo. Oddelek za muzikologijo Filozofske fakultete v Ljubljani, 59-63.

[Emil] [Adami]č, "Tri uspele glasbene prireditve. Slavnostna akademija 'Preporoda' [...] «. Slovenski narod 65 (21. dec. 1932) $288 \mathrm{a}, 3$. E. Adamič, prav tam.

6 "Dejanje se godi v velemestnem predmestju. Na cesto prideta fant in skromno dekle. Nezdravo ponočno ozračje tega kraja vpliva tako na fanta, da pusti svojo prijateljico in gre za Bivšo damo. Dekle je zaradi tega silno potrto in se v obupu zgrudi na tla. Bohem, ki je nekaj časa opazoval njeno duševno borbo, ji priskoči na pomoč. Dekletovo, hvaležnosti polno srce, pa se obrne k njemu, kjer najde vso oporo. Kmalu pa se povrne njen prejšnji fant, ki ju zaloti v prisrčnem objemu. V divji ljubosumnosti potegne nož, da bi obračunaval z nenadnim tekmecem. Dekle v zadnjem hipu ugane njegovo namero in, hoteč zaščititi bohema, se samo nastavi pod morilčev meč.» M. Bravničar (ur.), „Plesni večer«. Gledališki list NG v Ljubljani, Opera 1938/39, $17,122-123$. 
Opere. Scenarij in koreografija sta bila delo Petra Golovina, dirigiral je skladatelj. ${ }^{7}$ Pavel Šivic je tedaj ocenil skladbo, sicer bolj med vrsticami in v nasprotju od navdušenega Adamiča, s kančkom kritičnosti, oziroma z drugega zornega kota: »Plesna suita 'Cesta' istega skladatelja je vzbudila radi svoje kabaretnosti na odru zanimanje večine gledalcev. V glasbi pa je bilo deloma čutiti, da je skladatelj Žebre preveč umetnika, da bi se ponižal do prostaškega šlagerja, ki bi bil v skladu s sceno. Sploh pa je glasba pozitivistična umetnost, ki ji je mnogo dostopnejše ponazorenje lepega, idealnega in vzvišenega kot pa obratno. Zato zavede prekršitev tega dejstva rada v zvočne grobosti. $\aleph^{8}$ Obe omenjeni oceni držita, saj kažeta različni plati medalje. Prva upošteva glasbeno-zgodovinsko aktualnost in "naprednost " glede na slovenske razmere, druga pa glasbeno-estetski vidik. Skladateljevo pero je v želji, da bi zadostilo obema kriterijema, kot kaže partitura, iskalo ravnotežje med kategorijama »novega« in »umetniškega». Poglejmo podrobnosti.

\section{Oblika, napetostni procesi, stavčna gradnja}

Suito je Žebrè zasnoval kot svoboden niz štirih krajših "plesnih" stavkov z naslovi Marche, Valse, Tango in Blues. Njihova oblikovna zasnova je (tudi zaradi kratkosti) enostavna, pregledna in tradicionalna - pesemsko tridelna. Prvi in zadnji stavek se začneta s krajšim uvodom, ${ }^{9}$ tretji je izjemoma brez kode. Spremembo tempa beleži le četrti stavek, ko uvodnemu Maestosu sledi Allegro, sicer ostajajo predpisane hitrosti z izjemo manjših agogičnih sprememb v okviru posameznega stavka nespremenjene. Počasni in hitri stavek se dvakrat izmenjata v pravilnem zaporedju po vzoru starocerkvene sonate.

Potek napetosti v posameznih stavkih naznanja bodočega Žebreta, ki simfonično tkivo smiselno in jasno oblikuje $\mathrm{v}$ daljših potekih stopnjevanja napetosti in sproščanja. Z izjemo tretjega stavka (Tanga), ki je ostalim trem kontrasten zaradi pretežne napetostne statičnosti, posebne zamaknjenosti in dinamične monotonosti, so stavki naravnani stopnjevalno h končnemu višku v dveh gradacijah, z nenadnim padcem napetosti in začetkom nove gradacije ob nastopih druge teme. Recesije so torej nenadne, progresivno-recesivnih (ali obratno) lokovnih oblik v Suiti še ni. Značilna tudi za kasnejše skladateljeve orkestralne skladbe je začetna »udarnost « in končna recesivnost uvoda $\mathrm{V}$ prvem in četrtem stavku, ${ }^{10}$ kar ustvarja učinkovit kontrast nastopom prvih tem. Poteki gradacij so večinoma zvezni, ni večjih vmesnih nihanj napetosti, kar pogojuje nenazadnje tudi kratkost stavkov. V dramaturgiji napetostnih procesov posameznih stavkov in njihovi razvrstitvi je Suita domišljena celota. Glasen začetek (uvod) z nenadno in popolno sprostitvijo ob začetku prve teme je značilen za zunanja stavka (simetrija!), enak je tudi njun nadaljnji potek napetosti (dve gradaciji). Pri drugem stavku se kot posebnost zgodi nenadna recesija po ponovljeni prvi temi (A') pred kodo, s katero se začne novo stopnjevanje, tretji stavek pa je zaradi napetostno-statične narave ostalim trem kontrasten. Vprašanje je, ali je skladatelj slednjega umestil na najbolj učinkovito

\footnotetext{
Istega večera je bila kot balet uprizorjena tudi Žebretova Prva vizija za simfonični orkester. Gl. Henrik Neubauer. Vodnik po baletih slovenskih skladateljev. Ljubljana: Forma 7, 2000, 62 in 74. - Matija Bravničar, prav tam, 117-124.

[Pavel] Š [ivic], "Baletni večer«.Jutro 20 (20. jun. 1939) 140, 7.

Pri Valčku je ta zanemarljiv, saj obsega tri takte spremljave.

Pri 1. stavku je uvod progresivno-recesiven, pri 4. pa recesiven.
} 
mesto (mesto zlatega reza) v ciklu zavestno ali intuitivno. ${ }^{11}$ Vsekakor kasnejši orkestralni opus potrjuje njegovo upoštevanje univerzalnih lepotnih razmerij.

Če motivično-tematska enovitost v najstrožjem (tradicionalnem) pomenu besede velja le v okviru posameznega stavka, te poenoti enaka oblikovna zasnova, in med drugim, tudi stavčna gradnja na nižjih strukturnih ravneh. Ta je namreč dvovrstna, saj gre pri gradnji tem za istočasnost dveh principov. Prvi temelji na sestavljanju večjih celot prek ponavljanja ali variiranja taktov ter dvotaktij. Kaže afiniteto do klasicistične arhitektonske gradnje, medtem ko drugi uveljavlja evolucijski (razvojni) princip nastajanja melodičnih linij, s težnjo po neponavljanju taktovih vsebin in nenehnim nastajanjem novih, ki so s predhodnimi povezane zgolj z motivičnimi prvinami (submotivi) - bodisi z njihovo variacijo, permutacijo ali ponavljanjem. Žebrè ustvarja na ta način tudi kontrastnost med temami znotraj posameznega stavka. $V$ dveh primerih zgradi eno temo po prvem omenjenem načinu, drugo po drugem. ${ }^{12}$ Zanimiv je primer gradnje obeh tem v drugem stavku (Valčku): za ritem velja arhitektonsko načelo, za tonsko višino evolucijsko. ${ }^{13}$ Posebnost sta tudi tretji stavek (Tango), kjer dve strukturno kontrastni melodični liniji kontrapunktično skladatelj sooči že na začetku, ${ }^{14}$ in uvod prvega stavka, v katerem "arhitektonsko« grajenemu osemtaktju sledi »evolucijsko« dvotaktje. ${ }^{15} \mathrm{~V}$ skladu z obema vrstama tem so tudi njihovo členjenje, dolžina in stavčna gradnja posameznih tematskih delov. Pri »arhitektonskih« temah je členjenje periodično (simetrično), pri »evolucijskih» asimetrično. ${ }^{16}$ Prve so krajše, ponavadi štiritaktne celote (mali stavki), ${ }^{17}$ druge daljše ( 7 , 10, 13 ... taktni veliki stavki). ${ }^{18}$ Teme v obliki periode v odnosu vprašanje-odgovor so redkejše, gre pa za omembo vredna primera: prvega predstavlja evolucijsko grajena prva tema Koračnice, ${ }^{19}$ drugega pa najdemo v Valčku, kjer nastopi drugi del prve teme šele kot kontrapunkt k njeni variirani ponovitvi v tretjem delu (A'). ${ }^{20}$ Zanimiva je tudi zgradba B-teme v Tangu: je tridelna in evolucijsko grajena. Njen prvi člen se pojavi že kot kontrapunkt v A-delu, druga dva pa sestavljata dvodelni B-del (prvi od teh je kanon). ${ }^{21}$ V okviru navidezne oblikovne jasnosti in povsod iste simetrične tridelnosti (ABA') se na nižjih strukturnih ravneh tako razkriva domiselno raznolika oblikovanost posameznih delov (odsekov). A-deli so krajši in v vseh stavkih približno enako dolgi, zapolnjujejo jih teme same (od 11-14 taktov); najkrajši (9 taktov) je ta del v četrtem stavku, kjer je tudi prva tema kratka (4 takti) in enkrat dosledno ponovljena. B-deli so daljši, njihove dimenzije se od začetka do konca suite povečujejo (11, 32, 52, 61 taktov). Žebrè jih tudi gradi v vsakem stavku drugače: s trikratnim nastopom teme (dosledna melodična ponovitev) v prvem stavku; s témi dodanima dvema, motivično soodvisnima in različno

\footnotetext{
Če začetek in konec vsakega stavka oštevilčimo, se tretji stavek začne na točki pet od osmih.

Gl. "arhitektonsko« prvo in »evolucijsko« drugo temo 4. stavka; obratno velja za 1. stavek.

Gl. vl. 1, t. 4-16 in tr., t. 17-29.

Prim. »evolucijsko« melodijo klarineta in »arhitektonsko« temo violin, v kateri se prvo štiritaktje sekvenčno ponovi, t. 1-13.

Gl. 1. stavek, t. 1-10.

Členjenost npr. teme klarineta v Tangu je $3+4+23 / 4+23 / 4$ (t. $1-13), 2$. teme v Valck $u$ 2,5+3,5+2,5+3,5 (t. 17-29), 1. teme v Koračnici $3+4+2+2+2$ (t. 11-23).

Gl. prvo temo v 1. stavku (t. 24-27) in A-temo v 4. stavku (t. 4-7).

Prim. prvo temo 1. stavka (t. 11-23), temo klarineta v 3. stavku (t. 1-13), drugo temo 4. stavka (t. 13-22).

Prvi del nastopi v trobenti, drugi pa v trombonu (t. 11-23).

Gl. linijo trobent in trombona v t. 48-58.

1. del B-teme gl. cl., t. 1-13, 2. del gl. vl. 1, t. 14-49, 3. del gl. vl. 1 in 2, t. 50-65.
} 
dolgima (evolucijsko variiranima) stavkoma v drugem; s štiriglasnim kanonom v tretjem in s sekvenčnim (transponiranim) ponavljanjem teme ter njenim postopnim krajšanjem, ki ima učinek strette, v četrtem stavku. V tretjem delu (A') so teme melodično le redko variirane, pogosto gre za dosledne ponovitve, vendar z drugačno teksturno, harmonsko in/ali instrumentacijsko obravnavo, ki se od stavka do stavka razlikuje. V Koračnici se začne ta del s sočasnim strettom A in B-teme ob dodani novi kontrapunktični liniji ("Ctemi«), nad katero se nato zvrstijo A-tema in motivi B-teme v kontrapunktičnem triglasju. ${ }^{22}$ V Valčku skladatelj A-temo kontrapunktično sooči z njenim »odgovorom «, ${ }^{23}$ V Tangu jo spremlja s fugatom prvega dela B-teme, ${ }^{24} \mathrm{~V}$ Bluesu pa jo zgolj instrumentacijsko ojača. ${ }^{25}$ Kode so kratki, nekajtaktni zaključki stavkov, brez posebne oblikovne teže.

Sonatnega konflikta tem in izpeljevanja gradiva v tradicionalnem smislu Suita ne pozna. Krajše izpeljevanje in bolj v zametkih je prisotno predvsem v B-delih, vsekakor pa so postopki obravnave tem baročni: kontrapunktično dodajanje glasov, dosledna ali variirana imitacija motivov oziroma tem v drugih glasovih, transpozicija, fugato in že omenjeni kanon.

Evolucijski način gradnje ni toliko odmev baroka kot težnja določene smeri nove glasbe, ki stremi k atematičnosti. »Evolucija« v Suiti za razliko od baročne domala ne pozna sekvenciranja na najnižjih ravneh oziroma ponavljanja submotivov, ampak nenehno variacijsko razvijanje. Tudi baročna "suitnost kot zaporedje plesnih stavkov z izmenjavo kontrastnih tempov (počasi-hitro-počasi-hitro) in metrumov $(3 / 4,2 / 4,3 / 4, \mathrm{C})$ je predrugačena - z ohlapno motivično-tematsko povezanostjo in pretežno (nebaročno) tridelnostjo. Poleg za novo glasbo značilne nove teksturne kompleksnosti oziroma linearne neodvisnosti raznorodnih teksturnih plasti, posebne teksturne večplastnosti pa so nekateri postopki stavčne gradnje, ki zadeva vertikalne odnose, dosledno baročni. To velja za štiriglasni kanon na začetku srednjega (B) dela Tanga, ${ }^{26}$ motorično-kinetično ritmično zanesenost »evolucijskih«linij, za imitacijo in kontrapunktično vodenje glasov, kot tudi za zaporedje stavkov počasi-hitro-počasi-hitro po vzoru baročne sonate.

\section{Melodika, harmonija, ritem in metrum}

Melodično-harmonske tonske strukture so v Suiti najdrznejši element kompozicijskega stavka. Če je melodika v okvirih zmerno modernističnih tehnik neoklasicistične estetike, se vertikalne zvočne kombinacije ponekod »odpirajo « avantgardističnim nastavkom. Disonančni zvok ustvarjajo v prvi vrsti trenja med različno tonalno osrediščenimi teksturnimi plastmi, enoglasno-melodičnimi ali akordskimi ter hitra menjava tonik znotraj njih. Posamezna teksturna plast je vsaka zase jasno tonalno osrediščena. Če gre za enoglasne melodične strukture, so te pogosto razrezane na manjše celote, ki temeljijo na tonih ene diatonične lestvice, za krajši ali daljši čas, odvisno od ritma menjave tonskega območja v horizontali. Njihova zaporedja so svobodna, ne sledijo zakonitostim funkcionalne tonalnosti. Enako velja za akordične teksturne plasti - gradniki, iz katerih

Gl. 1. stavek, t. 35-50.

Gl. linijo tr. in trb. v 2. stavku, t. 50-58.

Gl. linijo fl. 1 in 2 v 3 . stavku, t. 66-79.

V prvem delu (A) jo izvajata fl. in cl., v zadnjem (A') pa tudi ob., fg. in vl. Gl. 4. stavek, t. 74-91.

Oktavno-kvartni štiriglasni kanon s padajočim vstopom glasov (fis2 $\rightarrow$ fis $1 \rightarrow \Pi$ cis $1 \rightarrow \Pi$ cis). Gl. Tango, t. 14-49. 
so sestavljene, so preprosti tonalni idiomi (durovi in molovi trozvoki z obrati, dominanti septakordi ...) v funkcionalno nevezanem zaporedju. Pri vsem tem je najpomembnejša predvsem vertikalna sočasnost takšnih teksturnih komponent, ki v vertikalni (harmonski) kombinaciji posledično, navidez pa povsem slučajno, povzroča disonančno zaostrene intervalne kombinacije ( $\mathrm{m} 2, \mathrm{v} 7, \mathrm{zv} 4, \mathrm{~m} 9)$. Osnovna ideja je torej politonalnost oziroma polikordalnost, raznotera tonikizacija horizontale in vertikale.

Nekatere teksturne plasti in akordi pa so že sami po sebi zasnovani kot atonalni strukturni gradniki: to so, denimo kvartni akordi, ${ }^{27}$ sozvočja iz kvint, ${ }^{28}$ akordi z dodano zvečano kvarto, ${ }^{29}$ zmanjšano oktavo ${ }^{30}$ in podobno. Sicer je večina sozvočij terčno razložljivih, čeprav so nemalokrat toni v njih razvrščeni bodisi neterčno bodisi bikordalno. Zelo pogosti akordski strukturi v polikordalnem okolju sta durov ali molov trozvok z obrati in dominantni septakord brez razvezov, vendar tonalni idiomi v politeksturnem naslojevanju nimajo tonalnega harmonskega učinka, zato vertikalna sozvočja in njihova zaporedja zvenijo zunajtonalno in disonančno.

Melodika je neoklasicistično parodična, z elementi groteske, humorja in satire. Karikira tedaj modne plese s tonalno segmentiranimi (razrezanimi) melodičnimi linijami na eno- ali večtaktne »celice«, z vedno drugim tonalnim centrom. Včasih pa je melodična linija zasnovana kromatično (atonalno), s težnjo čim hitrejšega zapolnjevanja kromatičnega prostora. ${ }^{31}$ Verjetno ni naključje, da Koračnica spominja po tonikalno spremenljivi melodični liniji na tisto iz opere Zaljubljen v tri oranže Sergeja Prokofjeva, ki je doživela leta 1927 v ljubljanski operi 22 predstav. ${ }^{32}$ Naslednjega leta so izvedli še Oidipus Rex Igorja Stravinskega, ${ }^{33}$ leta 1928 pa Jonny igra Ernsta Křeneka. ${ }^{34}$ Žebrè je nekaj od tega zagotovo slišal. Po mnenju Boruta Loparnika je bil »konstruktivizem, kakor so imenovali novoklasicistični idiom (to 'napredno smer') kratko malo edina resnejša moderna izkušnja, ki se je od Osterčevega prihoda 1927. leta ponujala na ljubljanskem obzorju«.35

V Suiti se zakoliči tudi Žebretov ritmično-metrični prostor, ki z manjšimi nihanji v eno ali drugo smer ostaja enak do zadnje orkestralne skladbe. Predvsem gre za soočanje dveh skrajnosti, svojevrstne ritmično-metrične dvojnosti: ostinatno okostenele, simetrične in taktne metrike ter skrajno ritmično variabilne (evolucijske), netaktne asimetrije. Sinkopa, siceršnje premeščanje poudarkov znotraj normativnega metruma, ki se domala ne spreminja (znotraj posameznega stavka), in punktirane vrednosti ostanejo bistvena značilnost njegovih tematskih melodičnih linij tudi v kasnejšem opusu, ob nekaterih drugih ritmičnih posebnostih, kot so triole, kvintole, sekstole ipd. Neskončna linearna ritmična kombinatorika in prikrita horizontalna polimetrija nakazujeta izjemno skladateljevo ritmično-metrično invencijo, značilno tudi za kasnejši orkestralni opus. Sta sestavni del

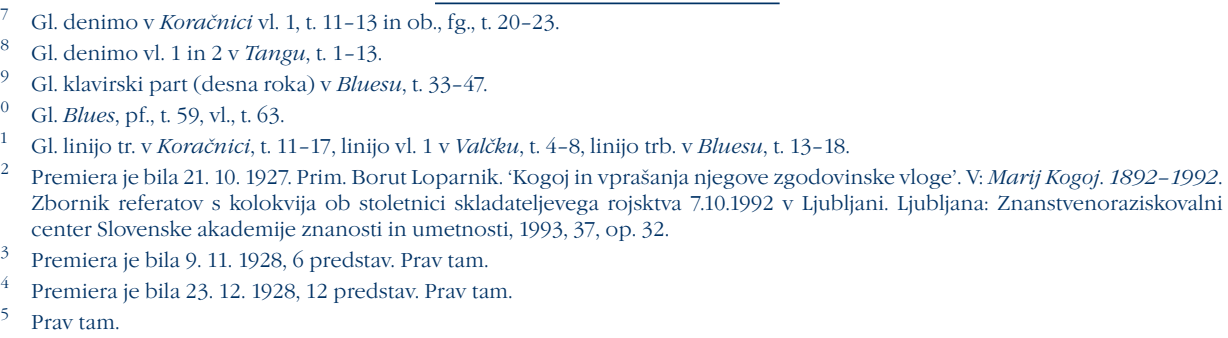


težnje po tematskem razvijanju - atematičnosti (v nekaterih skladbah) oziroma evolucijski stavčni gradnji, ki se v Suiti, kot smo videli, še druži z arhitektonsko. Po drugi strani gre (ne le v Suiti) za ritmične posebnosti jazzovske glasbe, ki se v nekaterih kasnejših delih odrazi manj, v drugih bolj prikrito. Zagotovo pa je ta v Suiti zavestna osnova Bluesu, v katerem ga skladatelj z banalno-enostavno prvo temo in orkestracijo močno parodira; drugače vsaj ni mogoče razumeti njenega cenenega učinka, oziroma bi ga bilo težko ločiti od naivno-začetniškega in estetsko neokusnega spodrsljaja.

V Suiti so tudi zametki Žebretove kasnejše teksturne (vertikalne) poliritmije ter polimetrije oziroma ritmično-metrične polifonije, ki doseže višek v Teku in Toccati, kjer se polifonsko naslojevanje različnih melodičnih linij na določenih mestih številčno poveča do skrajnih meja.

\section{Tekstura in orkestracija}

Kot je skladatelj ob »tradicionalnem« vključeval v glasbeno strukturo »nove« idiome pri stavčni gradnji, melodiki, akordiki, ritmu in metru ter z njimi namerno soočal »harmonični« gestus Z »neharmoničnim«, »konsonančno« z »disonančnim«, je v skladbi očitna tudi težnja po iskanju grobih (rezko zvenečih) zvočnih učinkov. K temu izdatno prispeva ob instrumentaciji posameznih glasov tudi teksturna razplastenost na harmonsko in ritmično neodvisne komponente, ki k ostrini zvoka "pripomorejo « $\mathrm{Z}$ disonančno zaostritvijo vertikale. »Polifonija« teksturne večplastnosti ostane Žebretova konstanta do konca, enako kot ostinatnost nekaterih teksturnih komponent. Čeprav s temi skladatelj v Suiti ponekod pretirava do meja neokusnosti, jih razume kot učinkovito iznajdbo antiromantične »nove stvarnosti« - kot cilj, ki opravičuje sredstvo. V nasprotju z romantistično harmonsko blagozvočnostjo in zvočno-barvno »zlitostjo s sodi tako skladba odločno med glasbeno-estetske produkte "nove« glasbe, z očitno navezo na osterčevski neoklasicizem.

Homofonija kompletne vertikale, tako značilna za romantične partiture, je redkost, homofonsko so zasnovane le posamezne teksturne plasti, ki skupaj s "polifonskimi« ustvarjajo kompleksno, za "novo« glasbo ne več tako novo, za Žebreta pa značilno teksturo. Tekstura in instrumentacija sta že v tej skladbi (ob ostalih strukturnih elementih) tudi pomembno sredstvo diferenciacije glasbenega toka - členjenja na višjih strukturnih ravneh ter napetostnih procesov. V Koračnici je, denimo homofonski samo uvod, ki pa sploh ne zveni blagozvočno in "ubrano« zaradi ostrine nekaterih disonančnih intervalov (m2, 4, zv4), ki sestavljajo vertikalo, ker je v funkciji progresivne napetosti uvoda in takšna je tudi instrumentacija: prvi del zaznamuje fanfarno triglasje trobent in pozavne, drugega pa petglasna homofonija godal, zvočno zaostrena s teksturno gostoto in kvartno razvrstitvijo nekaterih akordov. ${ }^{36}$ Postopnim gradacijam je imanentno teksturno zgoščanje - polifonsko dodajanje glasov ali plasti, povečevanje teksturnega števila, gostote in obsega. Instrumentacija glavne melodične linije je raznolika, izbira glasbil se nanaša na značaj stavka, dela ali odseka in na njihovo funkcijo. V Koračnici, denimo, tem nikoli 
ne izvajajo godala, ampak so v ospredju trobila, ${ }^{37} \mathrm{~V}$ Valčku godala, pihala in trobila, ${ }^{38} \mathrm{~V}$ Tangu godala, ${ }^{39} \mathrm{v}$ Bluesu pihala, ${ }^{40}$ vedno pa je zagotovljena zvočno barvna kontrastnost med A in B delom, oziroma sorodnost med A in A'. Ponavadi gre v A' za zvočno-barvno in teksturno stopnjevanje s povečevanjem števila in jakosti glasbil, če že ne za zvenenje celotnega orkestra. Predpisana velikost orkestra je med enojno in dvojno zasedbo instrumentalnih skupin. Trobila so brez rogov, v orkester pa je vključen tudi klavir, ki ima ob harmonski predvsem funkcijo tolkala. ${ }^{41}$ Suita je edina orkestralna skladba (razen Concertina za klavir in orkester) s tem glasbilom, tukaj po vzoru, denimo, Stravinskega. Skozi vse stavke ima klavir vlogo ritmično-harmonskega ostinata. Izjemoma se vključi v tematiko Valčka, kjer oktavno podvaja glavno melodično linijo. ${ }^{42}$

\section{Sklep}

Suita je groba kombinacija tradicionalnih in novih strukturnih idiomov. V nobeni drugi orkestralni skladbi ti ne bivajo eden ob drugem v tako nasprotujoči si (skrajni) obliki: diatonično ob kromatičnem, tonalno ob zunajtonalnem (atonalnem), homofonsko ob polifonskem, ritmično ostinatno ob skrajno ritmično diferenciranem, ponavljajoče se ob variacijsko razvojnem, konsonančno ob disonančnem, zvočno grobo ob zvočno zlitem. Parodičnost izraza se skriva prav v dialektični sočasnosti »trditve« in »negacije» večine kompozicijskih prvin.

Partitura poleg svojih posebnosti, izraza in sloga vsebuje tudi zametke značilnosti kasnejšega Žebretovega simfoničnega opusa v vseh strukturnih parametrih: variacijskost (razvojnost) melodike in ritmike, inkongruentno metriko, vertikalno in horizontalno polimetrijo, polnozvočno orkestracijo, "novo« tonalnost, »novo« akordiko, teksturo, enovitost motivično-tematske in siceršnje mnogoterosti ter mojstrstvo strukturiranja (napenjanja) daljših simfoničnih lokov. Skladba tako nakazuje bodočega Žebreta simfonika in razkriva njegov talent, kot »šolska vadnica" pa le ima nekaj pomanjkljivosti neizkušenega začetnika. Zvočni učinek Tanga in Bluesa skladatelju verjetno ni uspel tako, kot si ju je zamislil. Ritmično-metrično ozadje spremljevalnih teksturnih plasti je preveč enolično in okorno (tekstura in orkestracija!), prva tema Bluesa je kljub očitni nameri po enostavnosti na meji banalnega.

V stavkih Suite je Žebrè ohranil le ritmične prvine in značaj naslovnih plesov, melodično in harmonsko pa jih karikiral na način novoklasicističnega predrugotenja starih paradigm. Tango in Blues sta izrazit primer vpliva tedaj modnih plesov lahkotnejšega žanra. Kot prevetritev preživelega in "zatohlega" romantističnega izraza je bila popularna glasba eden od virov navdiha in glasbenega gradiva marsikateremu Žebretovemu

37 A-temo v prvem in tretjem delu igrata tr. in trb., B-temo, ki jo prvič tudi zaigrata trobenti, pa v gradaciji B-dela ponovita še fg. in fl., prav tako jo pihala zastopajo v zadnjem delu. Gl. t. 11-23 (A), 24-34 (B) in 35-50 (A'+koda).

38 Začne in konča se prvimi violinami (A in koda), B-del kontrastira s trobili in pihali, A' pa je kot višek stopnjevanja zvočno udarnejši s kombinacijo fl., ob. in pf.

39 Štiriglasni kanon srednjega (B) dela se zgodi v godalih (vl 1, 2, vla., vcl.), poleg tega violine igrajo A-temo v prvem in tretjem delu, obakrat pa jim kontrapunktira z B-temo eno pihalo - prvič cl., na koncu fl.

40 V prvem delu igrajo A-temo obe fl. in oba cl., v zadnjem pa vsa pihala skupaj s prvimi in drugimi vl. V srednjem delu po načelu kontrasta prevzamejo B-temo, ki je večkrat ponovljena v različnih "tonalitetah«, začetnemu trombonu kar trikrat godala. Gl. t. 13 -60.

41 Ob malem, velikem bobnu in činelah.

42 Ob fl. in ob., gl. t. 50-57. 
sodobniku, enako kot satira, groteska ali tehnicistično-modernistična (nova) stvarnost vsakdanjega življenja. Podobno ugotavlja slabih petdeset let po njenem nastanku tudi Pavel Mihelčič, namreč, da je bila tedaj skladba »tipičen produkt svoje dobe, oplojena z jazzom in modno zabavno glasbo, k čemur so se nagibali tudi nekateri slavni skladatelji; ta trenutek pa delo nima več tiste aktualne očarljivosti, čeravno je po tematski zasnovi duhovito, po orkestraciji pa dovolj tekoče«. ${ }^{43}$

Kljub nekaterim baročnim kompozicijskim postopkom je Žebrè v tej skladbi najbližji neoklasicističnemu izraznemu objektivizmu, po parodično-satirični vsebini pa nekaterim partituram Stravinskega ali Prokofjeva. O romantističnem lirizmu, impresionistični refleksiji ali ekspresionističnem subjektivizmu v Suiti ni sledu in prav po tem ta odločno odstopa od ostalega Žebretovega orkestralnega opusa, v katerem si je omenjena izraznost pridobila, sicer na različne načine in v različni meri, zopet »domovinsko« pravico, kot posledica skladateljeve drugačne, netrendovske in osebno zaznamovane izbire. Poleg tega je v Suiti očiten vpliv Osterčevega mentorstva. Verjetno ni naključje, da je bil ta v Žebretovih študijskih letih v neoklasicistično-baročni fazi kompozicijskega snovanja (od Suite za orkester, 1929 do Klasične uverture, 1934). Če je oceno Marijana Gabrijelčiča, da skladba »kljub pobliskom v tematičnih nanosih ne premore oblikovne ne izrazne intenzivnosti za današnji čas«, razumeti pogojno, saj ne vemo dovolj o njegovi predstavi "oblikovne in izrazne intenzivnosti za današnji čas«, velja pritrditi njegovi ugotovitvi, da skladba »ostaja dragocen glasbeno zgodovinski dokument «, ${ }^{44}$ še večji pomen pa ima kot izviren prispevek k fondu neoklasicistično-parodičnih in satirično obarvanih slovenskih orkestralnih skladb.

43 Pavel Mihelčič, „'Slovanski plesi' v odlični interpretacijik. Delo, 3. jun. 1980, 9. Kritika koncerta z dne 30. 5. 1980 (8. koncert modrega abonmaja, Velika dvorana SF, Orkester SF, dir. U. Lajovic).

44 Marijan Gabrijelčič, "Schumannova romantika«. Delo, 17. apr., 1991, 10. Kritika koncerta z dne 11. in 12. 4. 1991 (7. koncert modrega abonmaja, Cankarjev dom, Orkester SF, dir. Wolf-Dieter Hauschild). 